\title{
Plasticizer Contamination from Vacuum System O-rings in a Quadrupole Ion Trap Mass Spectrometer
}

\author{
Kent M. Verge and George R. Agnes \\ Department of Chemistry, Simon Fraser University, Burnaby, British Columbia, Canada
}

The outgassing of plasticizers from Buna-N and Viton o-rings under vacuum lead to undesired ion-molecule chemistry in an Electrospray Quadrupole Ion Trap Mass Spectrometer. In experiments with the helium bath gas pressure $>1.2$ mTorr, or whenever analyte ions were stored for $>100 \mathrm{~ms}$, extensive loss of analyte ions by proton transfer or adduction with o-ring plasticizers bis(2-ethylhexyl) phthalate and bis(2-ethylhexyl) adipate occurred. A temporary solution to this contamination problem was found to be overnight refluxing in hexane of all the o-rings in the vacuum system. This procedure alleviated this plasticizer contamination for $\sim 100$ hours of operation. These results, and those that lead to identification of the contamination as plasticizers outgassing from o-rings are described. (J Am Soc Mass Spectrom 2002, 13, 901-905) @ 2002 American Society for Mass Spectrometry

$\mathrm{T}$ he presence of low molecular weight neutrals that undergo charge exchange or adduction with analyte molecules can cause serious error in ion chemistry experiments in a mass spectrometer (MS). In our quadrupole ion trap mass spectrometer, the abundance of protonated molecules such as amino acids readily decreased during an ion storage period with simultaneous growth of background signals from $\mathrm{m} / \mathrm{z}$ 70 to 500 . Ions that did not decrease in intensity during ion storage were cations such as quaternary amines and Rhodamine $6 \mathrm{G}$, or compounds cationized by alkali metal ions such as poly(ethylene glycol) [1]. This suggested that there were neutral contaminants from one or more sources in our ES-MS that were efficiently stripping protons from protonated molecules injected into the ion trap, or the formation of adducts for ions that did not undergo charge exchange. In this work, we describe the identification of the source of prominent contaminants of nominal mass 370 and 390 Da.

Recent reports of contaminant problems in ion trapping experiments include increased chemical noise from compounds leached from plastic components used in the sample introduction system plumbing [2], diffusion pump oil contaminants that adducted with multiply protonated proteins [3], and neutral contaminants from an undetermined source that also formed adducts with multiply protonated proteins [4, 5]. Multiply protonated proteins are known to react at high

Published online June 13, 2002

Address reprint requests to George Agnes, Department of Chemistry, Simon Fraser University, Burnaby, B.C., V5A 1S6, Canada E-mail: gagnes@sfu.ca rates with gas phase bases [6]. A common factor in these reports was the storage of a population of ions prior to acquisition of a mass spectrum.

During the period of time in which the source and identity of these contaminants were being determined, it was not at all obvious that plasticizers outgassing from the o-rings of the mass spectrometer's vacuum system would eventually be identified as the source of this contamination. Plasticizers are however key ingredients in the fabrication of plastics, and as such they are ubiquitous in the environment [2, 7-19].

\section{Experimental}

\section{Electrospray Mass Spectrometry}

A quadrupole ion trap mass spectrometer (Model 3DQ, Teledyne, Mountain View, CA, USA) was fitted with an in-house constructed Electrospray (ES) ion source and a 2-stage atmospheric pressure gas sampling interface. The emitter for the ES ion source was either a stainless steel capillary of dimensions $15 \mathrm{~mm}$ long, $0.1 \mathrm{~mm}$ i.d. and $0.2 \mathrm{~mm}$ o.d., or a fused silica capillary (Polymicro Technologies, Phoenix, AZ, USA) of dimensions $30 \mathrm{~mm}$ long, $0.15 \mathrm{~mm}$ i.d. and $0.35 \mathrm{~mm}$ o.d. These capillaries were connected to a Swaglok union using nylon or graphite ferrules. The bias potential for the metal and fused silica capillaries were 2700-3700 and 4000-5000 V respectively (Model PS350, Stanford Research Systems, Sunnyvale, CA, USA). For the fused silica capillaries, the electrical connection was made to a metal couple 15 $\mathrm{mm}$ upstream of the capillary tip. The current passing through this power supply was monitored to ensure the 
absence of a discharge while ES-MS data were collected. The tips of these capillaries were positioned $\sim 10 \mathrm{~mm}$ from the counter electrode, which was biased to $300 \mathrm{~V}$. Sample solution in a syringe was delivered to the Swagelok union of the ES ion source at $5 \mu \mathrm{l} \mathrm{min}{ }^{-1}$ (syringe pump, Model 22, Harvard Apparatus, St. Laurent, $\mathrm{PQ}$, Canada). The connection tubing between the syringe and the union was either polyethylene (Becton Dickinson, Sparks, MD, USA) or fused silica. A sharpened stainless steel needle, biased to $4000 \mathrm{~V}$ was used to form a corona discharge. This ion source was used in replacement of ES in several experiments.

The base pressure of the mass spectrometer with no helium added was $2 \times 10^{-5}$ torr measured with an ion gauge calibrated for $\mathrm{N}_{2}$ (Model 342, Granville Phillips, Boulder, CO, USA). The operating pressure for the ion trap was set to a corrected pressure of $\sim 1 \times 10^{-3}$ torr by adding pre-purified helium through a leak valve.

Ions at atmospheric pressure were sampled first through a $75 \mu \mathrm{m}$ diameter orifice into a $\sim 1$ torr zone that was $10 \mathrm{~mm}$ long, and then through a second orifice that was $300 \mu \mathrm{m}$ in diameter. Ions passing through the second orifice were gated into the ion trap by a split middle electrode of an Einzel lens. The typical ion integration period used in this work was $1 \mathrm{~s}$ during which time the amplitude of the RF was held constant at a value corresponding to a $\mathrm{m} / \mathrm{z}$ cut-off of 30-45 Da [20-22]. The MS/MS software and electronics package bundled with this ion trap were used to isolate an ion population and when required, to extend the $m / z$ range of the instrument $[23,24]$. Access to the MS/MS functionality of the instrument was through a graphical interface that allowed the user to program any combination of sine waves in the range $10-500 \mathrm{kHz}$ at $1 \mathrm{kHz}$ intervals, with the amplitude of each sine wave selectable in the range $0-10 \mathrm{~V}_{\mathrm{p}-\mathrm{p}}$. Due to an electronics limitation, when more than one sine wave was selected for an isolation waveform, the user selected amplitude of each sine wave was divided by the number of sine waves selected. During ion acquisition, the RF amplitude was ramped linearly at $12 \mathrm{kDa} \mathrm{s}^{-1}$.

\section{Reagents and Consumables}

HPLC- and spectro-grade methanol and hexane were purchased from Aldrich, as were standard dioctylphthalate ( $99 \%$ purity), ferroin, acetic acid, and Ltryptophan. Ferroin, 1,10-Phenanthroline Ferrous Sulfate, is abbreviated here as $\left[\mathrm{Fe}^{2+}(\text { phen })_{3}\right]$. Buna-N and Viton o-rings were purchased from Kurt J. Lesker Company (Clairton, PA, USA).

\section{Soxhlet Extractions}

Plasticizers from new or used o-rings were extracted with a minimum of $200 \mathrm{ml}$ of spectro-grade hexane in a Soxhlet apparatus for periods up to 72 hours. Aliquots of the extract were taken at regular intervals during the refluxing and injected directly into a GC-MS.
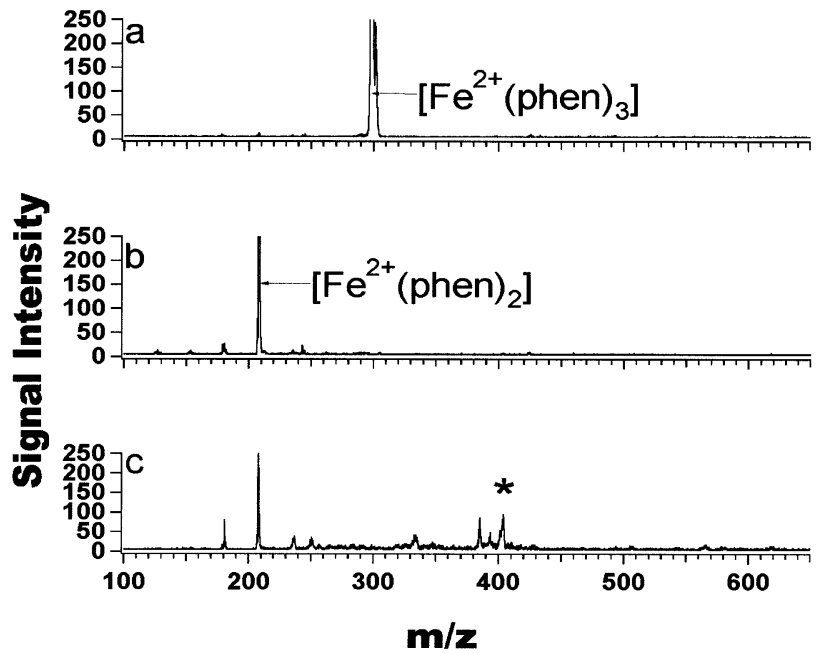

Figure 1. An $\mathrm{MS}^{\mathrm{n}}$ experiment showing adduction of contaminants to an ion stored in the ion trap mass spectrometer. (a) isolation of $\left[\mathrm{Fe}^{2+}(\mathrm{phen})_{3}\right],(\mathbf{b})$ fragmentation of the precursor ion $\left.\left[\mathrm{Fe}^{2+} \text { (phen }\right)_{3}\right]$ followed by isolation of a product ion, $\left.\left[\mathrm{Fe}^{2+} \text { (phen) }\right)_{2}\right]$, and (c) new ions formed by the adduction of contaminants to $\left.\left[\mathrm{Fe}^{2+} \text { (phen }\right)_{2}\right]$ after a storage period of $500 \mathrm{~ms}$. Base peak intensities were (a) 3700 for $\left.\left[\mathrm{Fe}^{2+} \text { (phen) }\right)_{3}\right]$, (b) 1200 for $\left.\left[\mathrm{Fe}^{2+} \text { (phen) }\right)_{2}\right]$, and (c) 400 for $\left.\left[\mathrm{Fe}^{2+} \text { (phen) }\right)_{2}\right]$. The peak marked by an asterisk is $\left[\mathrm{Fe}^{2+}(\text { phen })_{3}(\mathrm{DEHP})\right]$, see text.

\section{GC-MS}

The GC-MS (model G1800A GCD, Hewlett Packard, Palo Alto, CA, USA) was fitted with a HP 5MS column (30 m long, $0.25 \mathrm{~mm}$ i.d., and film thickness $0.25 \mu \mathrm{m}$ ). The column temperature program was a linear ramp from a starting temperature of $150^{\circ} \mathrm{C}$ at $10^{\circ} \mathrm{C} \mathrm{min}{ }^{-1}$ to a final temperature of $300^{\circ} \mathrm{C}$ and then held constant there for $15 \mathrm{~min}$. The ionization source was electron impact and the mass range of the instrument was scanned from 45-425 Da. Electron impact mass spectra were identified in part by database searches (Wiley Interscience, New York, NY).

\section{Results and Discussion}

Following the conversion of the ionization source for the quadrupole ion trap mass spectrometer from electron impact to ES by the addition of a two-stage atmospheric pressure gas sampling interface, planned ion-molecule experiments were precluded because of unwanted ion-molecule reactions between analyte ions and contaminants. The severity of this contamination is illustrated with mass spectra from an $\mathrm{MS}^{\mathrm{n}}$ experiment (Figure 1). A starting solution of $5 \times 10^{-5} \mathrm{M}$ ferroin in methanol was introduced to the ES ion source while generating these spectra. $\left[\mathrm{Fe}^{2+}(\text { phen })_{3}\right]$ was first isolated (Figure 1a) and then subjected to resonance excitation to cause it to undergo collision activated dissociation (CAD). Figure $1 \mathrm{~b}$ shows one of the product ions, $\left.\left[\mathrm{Fe}^{2+} \text { (phen) }\right)_{2}\right]$, following its isolation in the ion trap. The low intensity ions in Figure $1 \mathrm{~b}$ at $\mathrm{m} / \mathrm{z} 181$ and 236 were $\left[\mathrm{H}^{+}(\text {phen })_{1}\right]$ and $\left[\mathrm{Fe}^{+}(\text {phen })_{1}\right]$, respectively. The origin 
of these ions was from off-resonance absorption of the waveform used to isolate $\left[\mathrm{Fe}^{2+}(\mathrm{phen})_{2}\right]$, which caused a small fraction of it to undergo CAD after the isolation waveform ended. During a $500 \mathrm{~ms}$ delay period in which $\left.\left[\mathrm{Fe}^{2+} \text { (phen) }\right)_{2}\right]$ was stored in the ion trap, extensive adduction of gas phase contaminants to this ion occurred (Figure 1c). These contaminants ranged in mass from $\sim 70$ to $\sim 500 \mathrm{Da}$. Extension of this $\mathrm{MS}^{\mathrm{n}}$ experiment to higher values of $\mathrm{n}$ to isolate and fragment the complex at $\mathrm{m} / \mathrm{z} 404$ in Figure 1c regenerated $\left.\left[\mathrm{Fe}^{2+} \text { (phen) }\right)_{2}\right]$, and then with yet another delay period, the same complexes detected in the spectrum shown in Figure 1c were observed.

The neutral contaminants that adducted to $\left.\left[\mathrm{Fe}^{2+} \text { (phen) }\right)_{2}\right]$ to form the complexes at $m / z 393$ and 404 in Figure 1c were particularly problematic in different experiments that involved protonated analyte ions such as L-tryptophan. Rapid proton transfer from protonated L-tryptophan to the neutral contaminants $\left(C_{x}\right)$ to form $\left[\mathrm{C}_{\mathrm{x}}+\mathrm{H}^{+}\right]$occurred.

Our first attempts to eliminate this contamination problem were based on the work of Aebi and Henion who reported high background signals at low $\mathrm{m} / \mathrm{z}$ in CE-MS [2]. All plastic components of the sample delivery system were replaced with fused silica, and the methanol solvent used in the preparation of starting solutions was changed to spectro grade from reagent grade. Also, the metal electrodes and quartz spacers of the ion trap mass spectrometer were baked overnight at $500^{\circ} \mathrm{C}$. These measures to identify the possible sources of contamination in our ES-MS were unsuccessful.

The ES ion source was then replaced with a corona discharge needle to eliminate the possibility that our starting solutions and the sample introduction tubing for the ES ion source was a source of contamination. A corona discharge in air provides through a series of fast reactions protonated water clusters [25]. Abundant ion signals at $m / z 371$ and 391 remained in the spectra. This ion source was then placed inside a glass plenum chamber purged with a $1.0 \mathrm{~L} \mathrm{~min}^{-1}$ flow of pre-purified nitrogen. This was performed because the building in which our laboratory is located is plumbed with floor traps to localize chemicals spills in the event of an accident. When these drains are not flushed with water on a regular basis, this plumbing network becomes a conduit for vapors to spread throughout the building, and possibly into the mass spectrometer. A beaker containing distilled deionized water was placed inside the plenum chamber to provide a source of pure water vapor to stabilize the corona discharge. Signal intensities for the two principle contaminants, $\mathrm{m} / \mathrm{z} 371$ and 391, remained abundant (Figure 2) suggesting that the source of these contaminate ions $\left(\left[\mathrm{C}_{\mathrm{x}}+\mathrm{H}^{+}\right]\right)$was from inside the mass spectrometer.

The remaining sources for contamination were the turbo-molecular pump bearing lubricant, rotary vacuum pump oil, or outgassing from the foreline tubing and o-rings. Small sections of foreline tubing were placed into a beaker and refluxed in spectro-grade

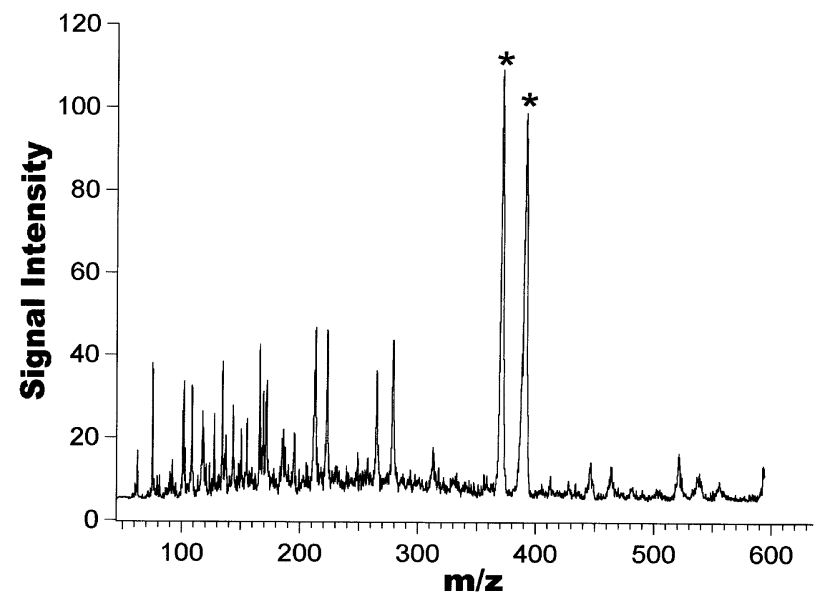

Figure 2. A mass spectrum of ions sampled from an atmospheric pressure corona discharge inside a plenum chamber purged with pre-purified $\mathrm{N}_{2}$. The two prominent contaminant ions denoted by asterisks were formed by proton transfer inside the ion trap.

hexane. Compounds extracted from the foreline tubing were identified by injecting $10 \mu \mathrm{L}$ volumes of the hexane solvent into a GC-MS. A high level of the plasticizer di-nonyl phthalate (M.W. 418.6) was identified in these extracts with a library search of its electron impact mass spectrum, but this was not a contaminant observed in spectra from either the ES or corona discharge ion sources. This result, together with the pressure gradients in the vacuum system, suggested that contamination from turbo-molecular pump bearing lubricant and the rotary vacuum pump oil was not likely.

An extraction of compounds from the Buna- $\mathrm{N}$ orings used to seal the ports on the vacuum system was then performed. Two compounds were extracted and both had high relative abundance in the GC-MS total ion current chromatogram. A library search of their electron impact mass spectra identified them both as plasticizers, bis(2-ethylhexyl) adipate (DEHA) (M.W. 370.57) which eluted at $t=11.5 \mathrm{~min}$ and bis(2-ethylhexyl) phthalate (DEHP) (M.W. 390.56) which eluted at $\mathrm{t}=12.2 \mathrm{~min}$. These same plasticizers were also identified in hexane extracts from viton o-rings.

Following identification of a source of the contaminants, all o-rings in the vacuum system were placed into a Soxhlet extraction apparatus. Hexane was added as solvent and the o-rings were refluxed overnight. The effectiveness of the removal process is illustrated with the data plotted in Figure 3 that show ion signal intensities for $\left[\mathrm{Fe}^{2+}(\text { phen })_{2}\right]$, produced in an MS/MS experiment from ferroin, and an adduct of this ion $\left(\left[\mathrm{Fe}^{2+}(\text { phen })_{2}(\mathrm{DEHP})\right]\right)$ as a function of storage time in the ion trap after formation of $\left[\mathrm{Fe}^{2+}(\mathrm{phen})_{2}\right]$. The plotted signal intensities were normalized to the intensity of $\left.\left[\mathrm{Fe}^{2+} \text { (phen }\right)_{2}\right]$ at zero delay time. Prior to refluxing the o-rings in hexane, $\left[\mathrm{Fe}^{2+}(\mathrm{phen})_{2}(\mathrm{DEHP})\right]$ grew to a maximum signal intensity within $1,500 \mathrm{~ms}$ of ion storage. Other contaminants also in competition for $\left[\mathrm{Fe}^{2+}(\text { phen })_{2}\right]$ restricted the maximum relative signal intensity of $\left[\mathrm{Fe}^{2+} \text { (phen }\right)_{2}$ (DEHP)] to $60 \%$ of the original 


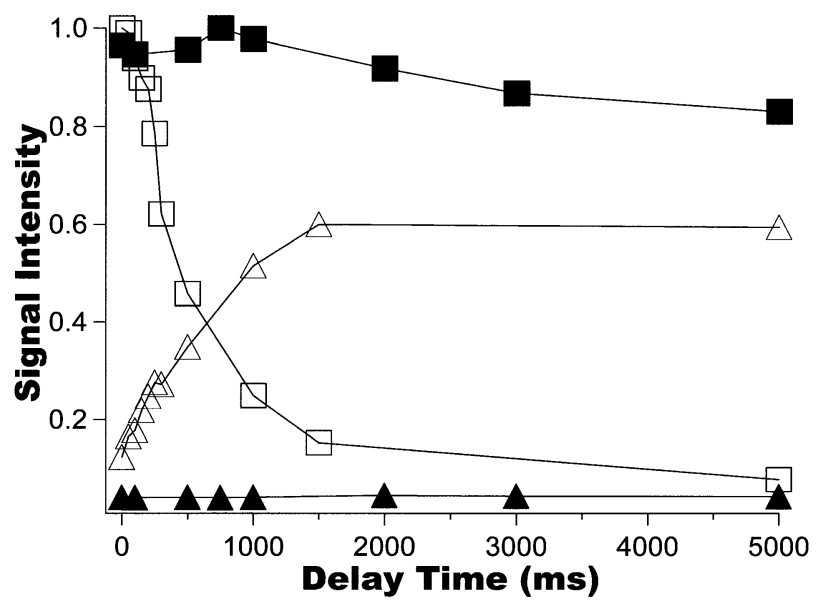

Figure 3. $M S^{\mathrm{n}}$ results showing plasticizer contamination in the ES-MS before (open symbols) and after (closed symbols) extraction of all o-rings by hexane in a Soxhlet apparatus. The data symbols from the ES-MS experiment represent the peak height of $\left[\mathrm{Fe}^{2+}(\mathrm{phen})_{2}\right](m / z=208)$ (squares) and $\left.\left[\mathrm{Fe}^{2+} \text { (phen) }\right)_{2}(\mathrm{DEHP})\right]$ $(m / z=404)$ (triangles).

base peak. After refluxing the o-rings, the signal intensity of the adduct peak remained small after $5 \mathrm{~s}$ of ion storage. The $10 \%$ decrease in signal intensity of $\left.\left[\mathrm{Fe}^{2+} \text { (phen }\right)_{2}\right]$ at the end of the $5 \mathrm{~s}$ delay indicated that other contaminants remained in the ion trap apart from the plasticizers extracted from the o-rings. For reference, a different ion, poly(ethylene glycol) cationized by sodium ion, that did not form an adduct or undergo charge exchange with the contaminants did not decrease in signal intensity over a $5 \mathrm{~s}$ delay.

Unfortunately, the refluxing of o-rings in hexane which alleviates the plasticizer contamination problem is only temporary. After $\sim 100$ hours of instrument operation, the same plasticizers from the o-rings reappear in the mass spectra. The cause of this is believed to be because plasticizers from the surface of the o-rings only were extracted by their refluxing in hexane. When a freshly refluxed o-ring was placed under vacuum, plasticizers from the interior of the o-ring slowly diffuse to the surface and outgas. In support of this finding, highly variable abundance of the two plasticizers were measured in the GC-MS total ion chromatogram in repeat extracts from a single o-ring. Extracts from new Buna-N or new viton o-rings also resulted in highly variable signal intensities of these two plasticizers.

Since the o-rings were determined as a major source of contaminants in our ion trap, we have been using one set o-rings for $\sim 3,000$ hours of operation, and during this time there have been 5 extractions using hexane in a Soxhlet apparatus without a change in the base pressure of the mass spectrometer. While this procedure did significantly alleviated the plasticizer contamination for short periods of time following the extraction, a more permanent solution would be to redesign the vacuum chamber for replacement of all rubber o-rings with metal o-rings.

\section{Acknowledgments}

Financial support was provided by The Natural Sciences and Engineering Research Council of Canada (NSERC) and Simon Fraser University.

\section{References}

1. Bogan, M. J.; Agnes, G. R. Poly(ethylene glycol) doubly and singly cationized by different alkali metal ions: Relative cation affinities and cation dependent resolution in a quadrupole ion trap mass spectrometer. J. Am. Soc. Mass Spectrom. 2002, 13, 177-186.

2. Aebi, B.; Henion, J. D. The reduction of cemical nise in an atmospheric pressure ionization/ionspray interface for mass spectrometry. Rapid Commun. Mass Spectrom. 1996, 10, 947-951.

3. Purves, R. W.; Gabryelski, W.; Li, L. The effect of using silicon based diffusion pump fluid on spectral quality in an electrospray ionization ion trap/time-of-flight mass spectrometer. Rev. Sci. Instrum. 1997, 68, 3252-3253.

4. Mao, D.; Douglas, D. J. H/D exchange of gas phase peptide and protein ions with a linear ion trap (LIT) time-of-flight mass spectrometer system. In Proceedings of the 49th ASMS Conference on Mass Spectrometry and Allied Topics: Chicago, Illinois, 2001, May 26-June 1.

5. Collings, B. A.; Campbell, J. M.; Mao, D.; Douglas, D. J. A combined linear ion trap time-of-flight system with improved performance and MSn capabilities. Rapid Commun. Mass Spectrom. 2001, 15, 1777-1795.

6. McLuckey, S. A.; Van Berkel, G. J.; Glish, G. L. Reactions of dimethylamine with multiply charged ions of cytochrome C. J. Am. Chem. Soc. 1990, 112, 5668-5670.

7. Holadova, K.; Hajslova, J. A comparison of different ways of sample preparation for the determination of phthalic acid esters in water and plant matrices. Int. J. Environ. Anal. Chem. 1995, 59, 43-57.

8. Salthammer, T.; Schwarz, A.; Fuhrmann, F. Emission of reactive compounds and secondary products from wood-based furniture coatings. Atmos. Environ. 1999, 33, 75-84.

9. Bauer, M. J.; Herrmann, R. Estimation of the environmental contamination by phthalic acid esters leaching from household wastes. Sci. Total Environ. 1997, 208, 49-57.

10. Staples, C. A.; Peterson, D. R.; Parkerton, T. F.; Adams, W. J. The environmental fate of phthalate esters: A literature review. Chemosphere 1997, 35, 667-749.

11. Manura, J. J. Detection and identification of volatile and semi-volatile organics in synthetic polymers used in food and pharmaceutical packaging. Proceedings of the 42nd ASMS Conference on Mass Spectrometry and Allied Topics: Chicago, Illinois, 1994, May 29-June 3.

12. Ziesmann, J.; Valterova, I.; Haberkorn, K.; Sanchez, M. G. D.; Kaissling, K. E. Chemicals in laboratory room air stimulate olfactory neurons of female Bombyx Mori. Chem. Senses 2000, 25, 31-37.

13. Tienpont, B.; David, F.; Sandra, P.; Vanwalleghem, F. Evaluation of sorptive enrichment for the analysis of phthalates in air samples. J. Microcolumn Sep. 2000, 12, 194-203.

14. Moulin, C.; Charron, N.; Plancque, G.; Virelizier, H. Speciation of uranium by electrospray ionization mass spectrometry: Comparison with time-resolved laser-induced fluorescence. Appl. Spectrosc. 2000, 54, 843-848.

15. Lay, J. O.; Miller, B. J. Plasticizers in Pacifiers: Direct determination by FAB-MS. Anal. Chem. 1987, 59, 1323A-1325A.

16. Bowers, M. D.; Parsons, M. L.; Clement, R. E.; Eiceman, G. A.; Karasek, F. W. Trace impurities in solvents commonly used for gas chromatographic analysis of environmental samples. J. Chromatogr. 1981, 206, 279-288. 
17. Junk, G. A.; Avery, M. J.; Richard, J. J. Interferences in solid-phase extraction using C-18 bonded porous silica cartridges. Anal. Chem. 1988, 60, 1347-1350.

18. Furtmann, K. Phthalate analysis as a tool for environmental assessment. Anal. Meth. Instru. 1995, 2, 254-265.

19. Ende, M.; Spiteller, G. Contaminants in mass spectrometry. Mass Spectrom. Rev. 1982, 1, 29-62.

20. Louris, J. N.; Amy, J. W.; Ridley, T. Y.; Cooks, R. G. Injection of ions into a quadrupole ion trap mass spectrometer. Int. J. Mass Spectrom. Ion Processes 1989, 88, 97-111.

21. McLuckey, S. A.; Van Berkel, G. A.; Goeringer, D. E.; Glish, G. L. Ion trap mass spectrometry of externally generated ions. Anal. Chem. 1994, 66, 689A-696A.
22. McLuckey, S. A.; Van Berkel, G. A.; Goeringer, D. E.; Glish, G. L. Ion trap mass spectrometry using high pressure ionization. Anal. Chem. 1994, 66, 737A-743A.

23. Kaiser, R. E.; Cooks, R. G.; Moss, J.; Hemberger, P. H. Mass range extension in a quadrupole ion trap mass spectrometer. Rapid Commun. Mass Spectrom. 1989, $3,50-53$.

24. Schwartz, J. C.; Syka, J. E. P.; Jardine, I. High resolution on a quadrupole ion trap mass spectrometer. J. Am. Soc. Mass Spectrom. 1991, 2, 198-204.

25. Shahin, M. M. Mass-spectrometric studies of corona discharges in air at atmospheric pressures. J. Chem. Phys. 1966, 45, $2600-2605$. 